\title{
A Study on Actual Cases for Internet of Things based Smart City
}

\author{
Seong-Hoon Lee ${ }^{1}$ and Dong-Woo Lee ${ }^{2 *}$ \\ ${ }^{1}$ Division of Information \& Communication, Baekseok University, 115, Anseo- \\ dong, Cheonan, Choong-Nam, Korea \\ ${ }^{2 *}$ Dept. of Computer Information, Woosong University, 226-2, Jayang-dong, \\ Dong-gu, Daejon, Korea \\ ${ }^{1}$ shlee@bu.ac.kr, ${ }^{2 *}$ dwlee@wsu.ac.kr
}

\begin{abstract}
The Internet of Things(IoT) is the internetworking of physical devices, vehicles, buildings and other items embedded with electronics, software, sensors, actuators, and network connectivity that enable these objects to collect and exchange data. The interconnection of these embedded devices is expected to user in automation in nearly all fields, while also enabling advanced applications like a smart grid and expanding to the areas such as smart cities. We describe Internet of Things related with smart city in this paper. Smart city is an urban development to integrate multiple ICT and Internet of Things solutions to control a city's infrastructures. We described actual cases of smart parking system, smart bin and smart streetlight that are parts of smart city.
\end{abstract}

Keywords: ICT, Internet of Things, Smart city, Sensor

\section{Introduction}

The Internet of Things(IoT) means that various devices connected to a network interact mutually. IoT is also called other names, such as M2M(Machine to Machine) and WoT(Web of Things). Although many standardization organizations including IEEE, ITU, $3 \mathrm{GPP}$ and IETF define IoT diversely, IoT is generally defined as a technology that can offer additional value to users, as things or devices are connected with the Internet. Daniel Giusto defined IoT as a concept enabling to achieve goal with organic communication of various objects or things existing surrounding us (RFID tag, sensor, cellphone, mechanical drive system) in a book, "Internet of Things."[1].

Kevin Ashton coined the term in 1999 while working at Auto-ID Labs (originally called Auto-ID centers, referring to a global network of objects connected to radiofrequency identification, or RFID)[2]. Typically, IoT is expected to offer advanced connectivity of devices, systems, and services that goes beyond machine-to-machine (M2M) communications and covers a variety of protocols, domains, and applications[3].

In 2013 the Global Standards Initiative on Internet of Things (IoT-GSI) defined a IoT as "the infrastructure of the information society."[4]. The IoT allows objects to be sensed and/or controlled remotely across existing network infrastructure[5], creating opportunities for more direct integration of the physical world into computer-based systems, and resulting in improved efficiency, accuracy and economic benefit[6]. When IoT is augmented with sensors and actuators, the technology becomes an instance of the more general class of cyber-physical systems, which also encompasses technologies such as smart grids, smart homes, intelligent transportation and smart cities.

When things are connected with the Internet, not only various values are offered, but various services can be made through data-based user customization and learning through

\footnotetext{
${ }^{* *}$ Corresponding Author
} 
data collection, observation or remote control online, and continuous management of one's own information. Figure 1 shows a basic concept of Internet of the Things.

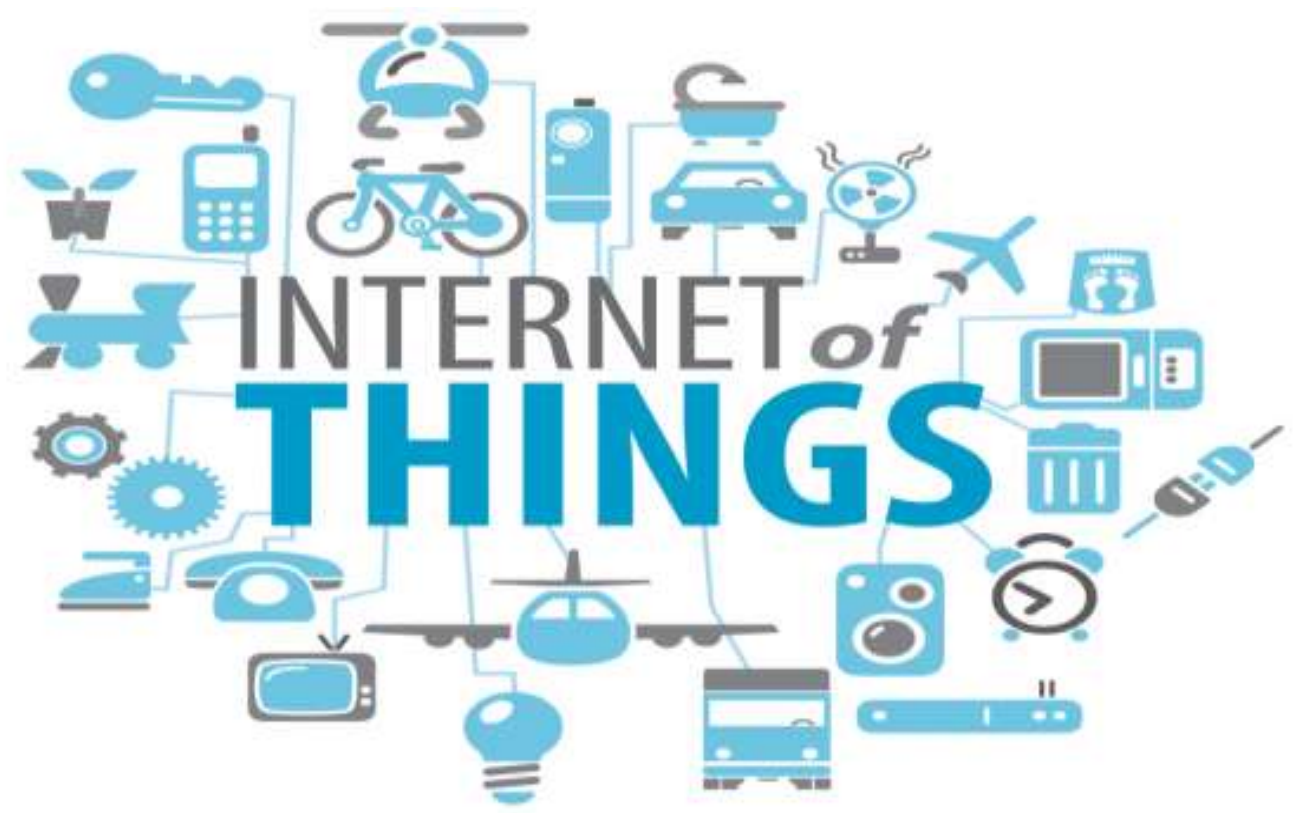

Figure 1. Internet of Things(loT)

Gartner, a global research firm, announces top ten strategic technologies having huge impacts in the following year in every October. Upon looking at the result, IoT is included in the technologies to affect from 2013 to 2015 as shown in Table 1. IoT can be the technology to gain continuous attention in the future.

Table 1. 10 Strategic Technology Trends from 2013 to 2015

\begin{tabular}{l|l|l}
\hline \multicolumn{1}{c|}{2013} & \multicolumn{1}{c}{2014} & \multicolumn{1}{c}{2015} \\
\hline Strategic big data & Smart machines & Smart machines \\
\hline Integrated ecosystems & Web-scale IT & Web-scale IT \\
\hline Actionable analytics & 3D printing & 3D printing \\
\hline Enterprise app stores & Software-defined anything & $\begin{array}{l}\text { Software-defined anything / } \\
\text { infrastructure }\end{array}$ \\
\hline IoT & IoT & IoT \\
\hline In-memory computing & Cloud/client architecture & Cloud/client computing \\
\hline $\begin{array}{l}\text { Mobile applications / } \\
\text { HTML5 }\end{array}$ & Mobile apps and applications & $\begin{array}{l}\text { Risk-based security / } \\
\text { self-protection }\end{array}$ \\
\hline $\begin{array}{l}\text { Hybrid IT / cloud } \\
\text { computing }\end{array}$ & $\begin{array}{l}\text { Hybrid cloud \& IT as a } \\
\text { service broker }\end{array}$ & $\begin{array}{l}\text { Advanced pervasive / } \\
\text { invisible analytics }\end{array}$ \\
\hline Mobile device battles & $\begin{array}{l}\text { Mobile device diversity / } \\
\text { management }\end{array}$ & Computing everywhere \\
\hline Personal cloud & Era of the personal cloud & Content-rich systems \\
\hline
\end{tabular}

As of 2013, about 10 15 billion things are predicted to be connected with the Internet, and the number of the things are forecast to persistently increase. Regarding such a phenomenon, our society is reaching the hyper-connected society, where all the surrounding things are connected each other through network. As the global population exceeds 7 billion at present, there must be a larger number of devices than that of humans. Such a countless number of devices are winged through the Internet and communicate 
with one another. In the early stage, of course, human manipulation will be the basis, but later on, such elements as Bluetooth, wireless communication, sensor data, and network help communication among themselves with human intervention gradually reducing. Cisco in 2011 announced the expected device numbers to be connected with Internet. Figure 2 shows foresee of device connection from 2003 to 2020.

If the IoT is built, the influence of IoT is expected to be expanded to daily life extensively, as well as all industries, due to technology development and diffusion of wireless networks, communication modules and sensors, and smart handsets. IoT is anticipated to bring about innovative changes to existing processes and services adopted in various fields including medical service, traffic, manufacturing and education.

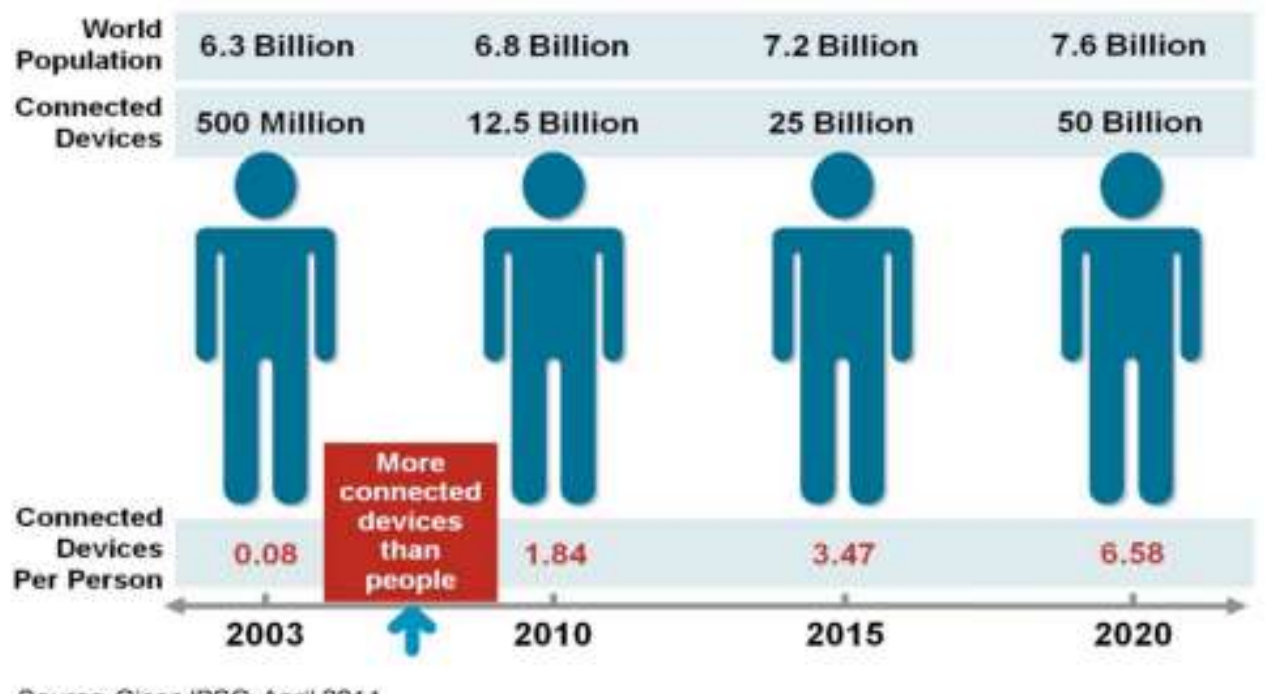

Source Cisco IBSG. April 2011

Figure 2. Foresee for Device Connection

\section{Internet of Things in Smart City}

This chapter discusses the details of utilization concerned with smart city in which IoT emerges as a major area. People who move from small cities to large cities rapidly increase for economic activities, such as education for children or employment. Therefore, such problems as mega city phenomenon, city infrastructure construction cost increase and environmental problems are on the rise. As an alternative to solve such problems, the smart city centered on urban administrators has emerged. For the smart city, various sensors-related technologies and ICT-based technologies are needed.

A smart city in the U.K. started, as a smart city proposal contest was executed targeting each local government in 2012. As a result, amid competition of some 30 local governments, Glassgow region was selected finally. The region received 24 million British pounds as subsidy from the government, and is building an intelligent system in order to comprehensively manage city's traffic, energy, environments and crime problems through collaboration with IBM. Starting with Glassgow, the British government plans to continuously build smart cities in major cities including London, Birmingham and Sunderland. The city of London is implementing the smart city construction through cooperation with Intel: Collecting and making such information as noise, air pollution and energy use rate data is implemented by attaching special sensors to the major facilities including city's buildings or streetlights. As work to lay the infrastructure to realize smart city, the connection of ten major cities with high speed communication network is carried 
out by performing a super-connected city project. We dealt with a specific domain of smart city such as smart parking system, smart bin and smart streetlight.

\subsection{Smart Parking System}

\subsubsection{Spain}

As part of implementing the smart city project in Barcelona, Spain, a so-called Live Project was implemented until 2012 as a program to promote electric vehicle consumption. The project aimed to improve environmental problems by promoting the electric vehicle use. Toward this end, collaborations were carried out with various private companies, such as IDAE and Siemens, including the state governments. Starting with this project, the city hall intended to increase the use of electric motorcycles and private electric vehicles, as well as electric vehicles for public and corporate uses. Since 2013, Barcelona has built a smart city solution, based on IoT technology in the city center, and has conducted its pilot operation. To this end, Sysco installed a network so that the wireless Internet can be conducted, and many ICT companies offered various technologies, such as sensor and data collection, analysis, position information and cloud service. The major services related with smart city offered by Barcelona are as follows:

Smart parking application, Parker: As a parking-related smartphone application utilizable in Barcelona, a service letting users know about vacant parking space is offered. When a user connects to the App, the information on where and how many parking spaces are available is offered in real time. A driver can save time and fuel, and the city can ease traffic jam by locating available parking spaces for drivers.

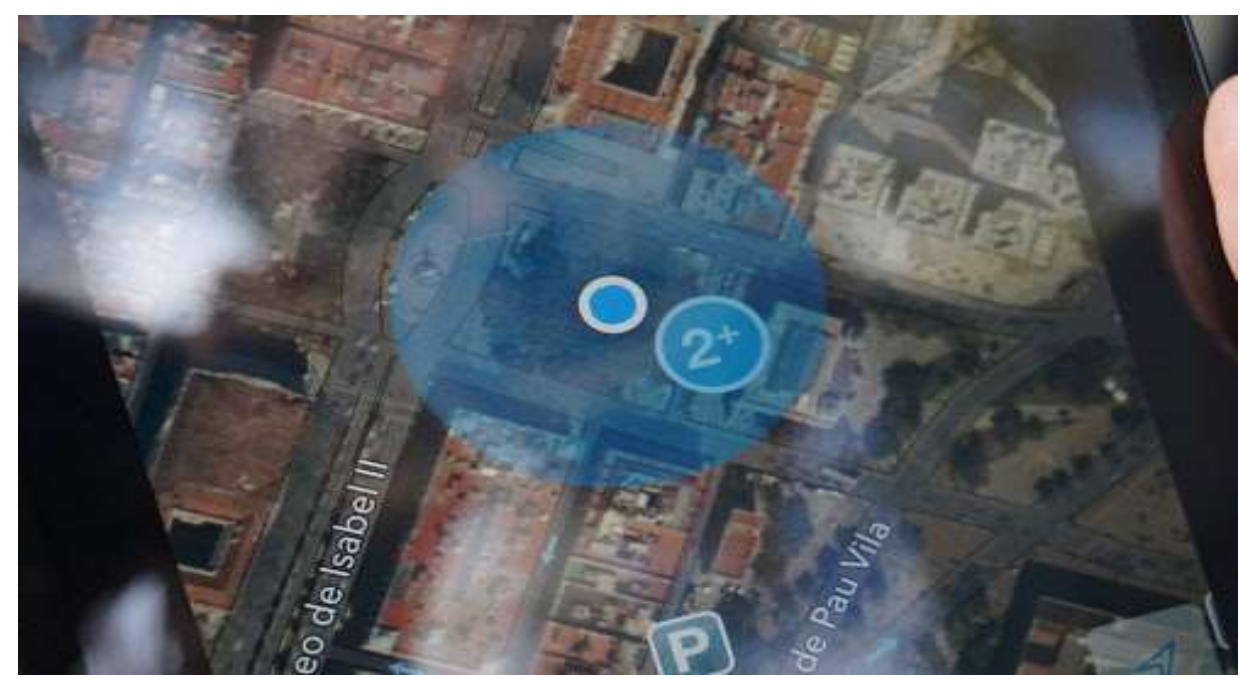

Figure 3. Parker in Barcelona

Smart parking system aims to offer a service on the status of parking space availability to the users by sensing whether vehicles are currently parked using a sensor with $15 \mathrm{~cm}$ in diameter under the asphalt for vehicle use. The operation of the sensor is seven years maximum, and the sensor is operated with self-power generation, and can detect metal with the mounted magnet. The sensor is connected with wireless Wi-Fi installed in the surrounding area. When a vehicle is parked, the information is sent to the data center, and is reflected in the App through the central control system. 


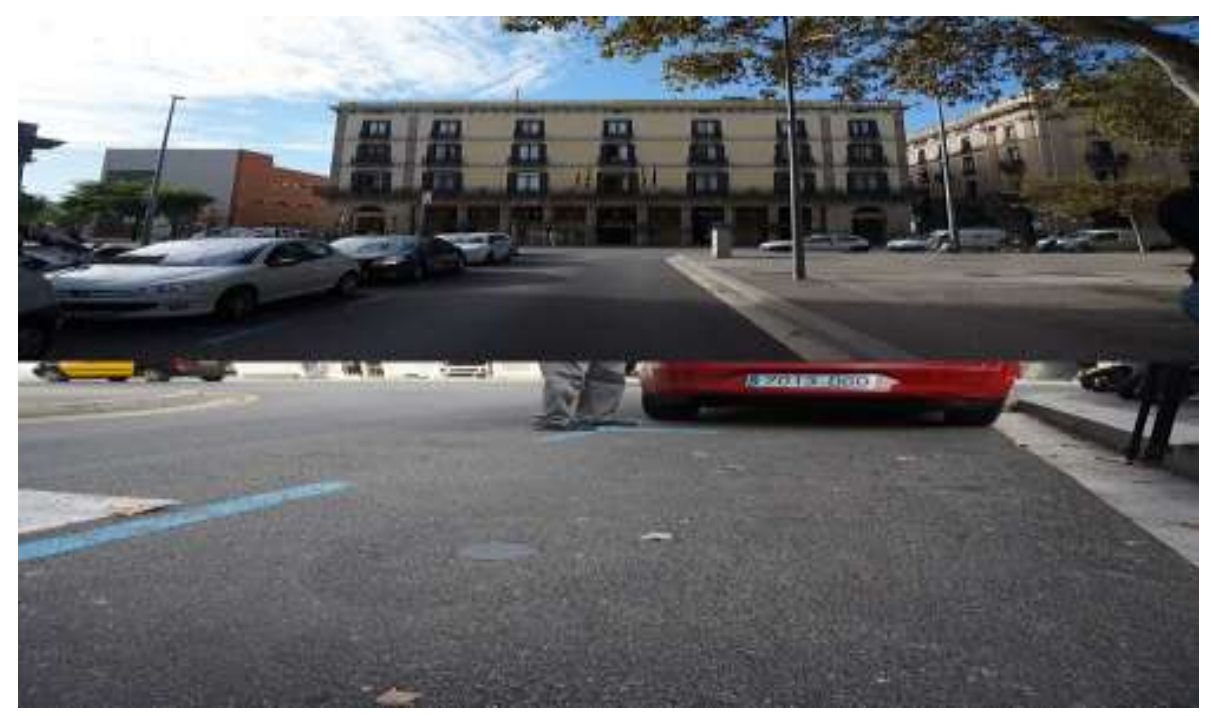

Figure 4. Parking Sensor in Barcelona

\subsubsection{United State}

Finding parking space in the city center of Los Angeles is predicted to be easier. LA Department of Transportation (LADOT) expands its ExpressPark Program, implemented to solve downtown traffic jam and parking difficulties, to other regions in the following year. The City of LA judged that the program for downtown parking management system operated for the past two years was successfully implemented, and decided to expand the program to Hollywood (900) and Westwood (500) in 2015, and Venice (700 900) in 2016.

The ExpressPark Program is a pilot program that began to efficiently manage 6,300 public parking spaces in China Town, Little Tokyo, Civic Center and Central Business District in June 2012. The city installed wireless sensors and smart meters in the street parking and public parking lots, and guided drivers to easily find parking spaces using the Website(www.laexpresspark.org) or smartphone App.

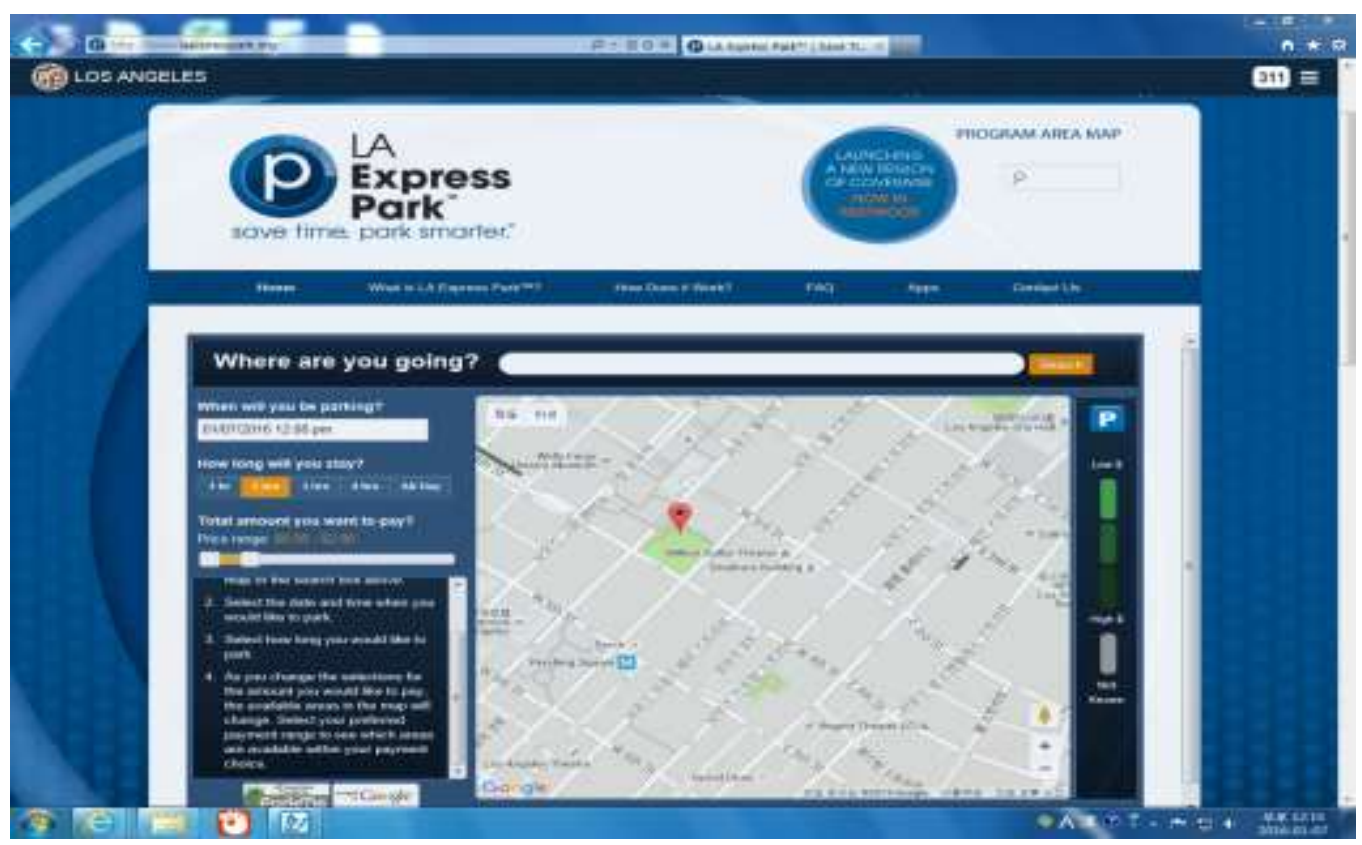

Figure 5. Website of LA ExpressPark 
Vacant parking spaces are updated in real time, and parking fees are adjusted from USD 1 to USD 6 diversely and periodically by time slot with much demand, and the program helps drivers quickly find parking spaces judged to be reasonable in terms of parking fee. If the parking fee of the parking space that one wants is slightly expensive, the driver can go to a parking space a bit away from his/her location.

The Express Park mobile APP can be downloaded for free, and there are three types: Parker, ParkMe and ParkMobile. The City of LA injected USD 18.5 million including federal government's subsidy USD 15 million for the development of the program.

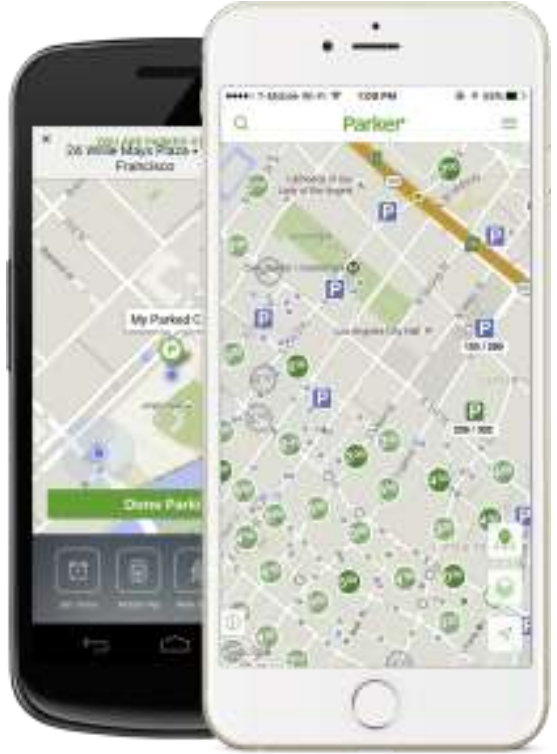

(a) Parker

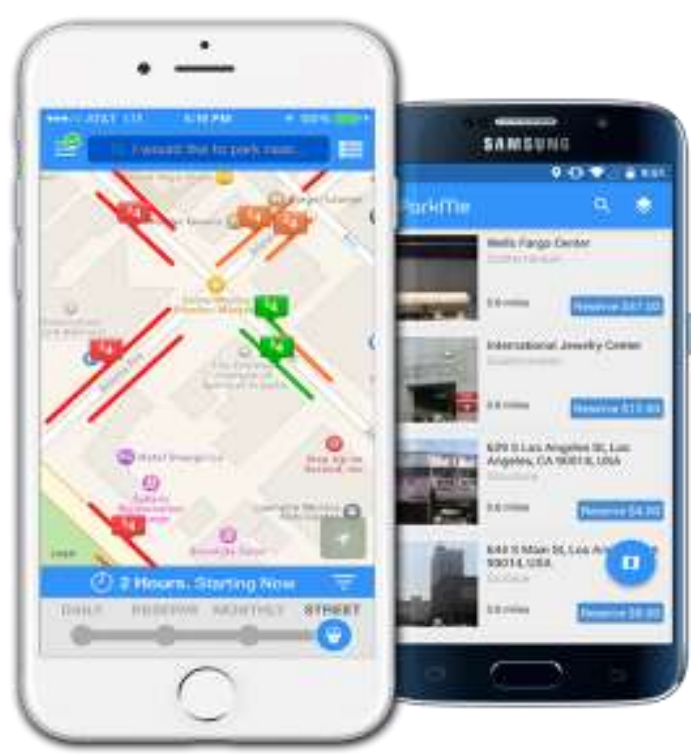

(b) ParkMe

Figure 6. Parker, ParkMe in LA
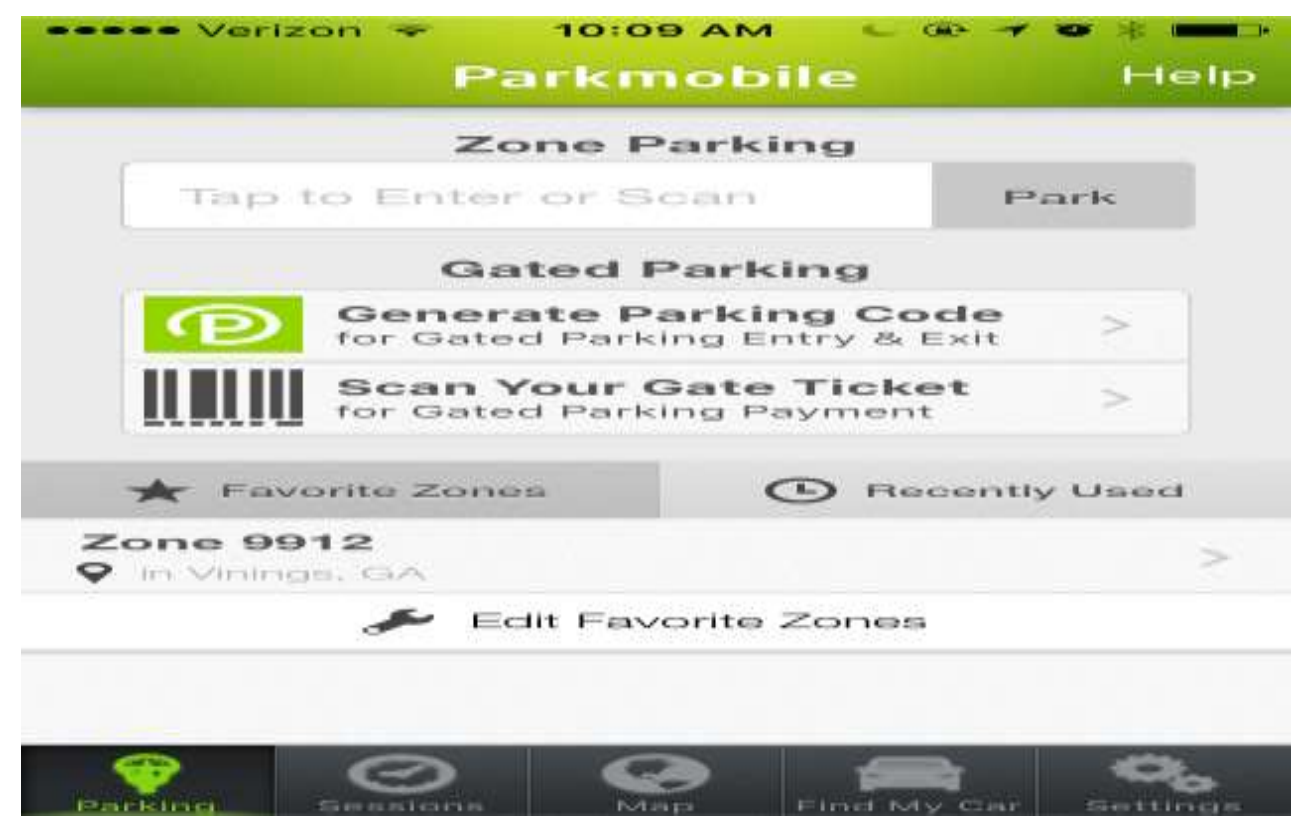

Figure 7. Parkmobile in LA

LADOT lowered average parking fees, raised parking space occupancy ratio, and increased relevant tax revenue by $2.5 \%$ for the past two years through such parking management. In the first year of the program execution (2012-2013), average parking fee 
fell from USD 1.95 to USD 1.74, and average parking space occupancy ratio rose to $17 \%$, according to the explanation of the LADOT. Currently, the average parking fee is USD 1.81 per hour.

LADOT forecasts that more developed type of parking management can be carried out including parking fee payment within a vehicle through smartphone or vehicle-installed navigation system, due to IT technology development.

\subsection{Smart Bin \& Smart Streetlight}

Smart bin: A sensor attached to the top part of a bin measures the weight of waste, and the information is sent to the waste collection drivers. Through this system, the waste amount can be known without naked eye confirmation on what level waste is in a waste bin. Fig 8 is a smart bin used in UK. Fig 9 shows multiple smart bins used in UK. Fig 10 shows a main concept of smart bin used in Barcelona.

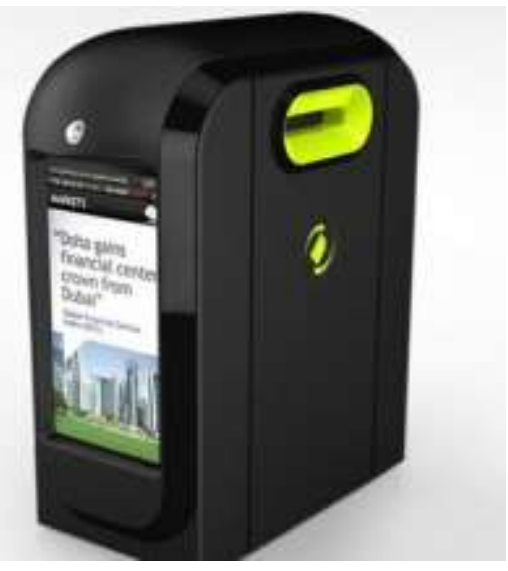

Figure 8. Smart Bin Used in UK

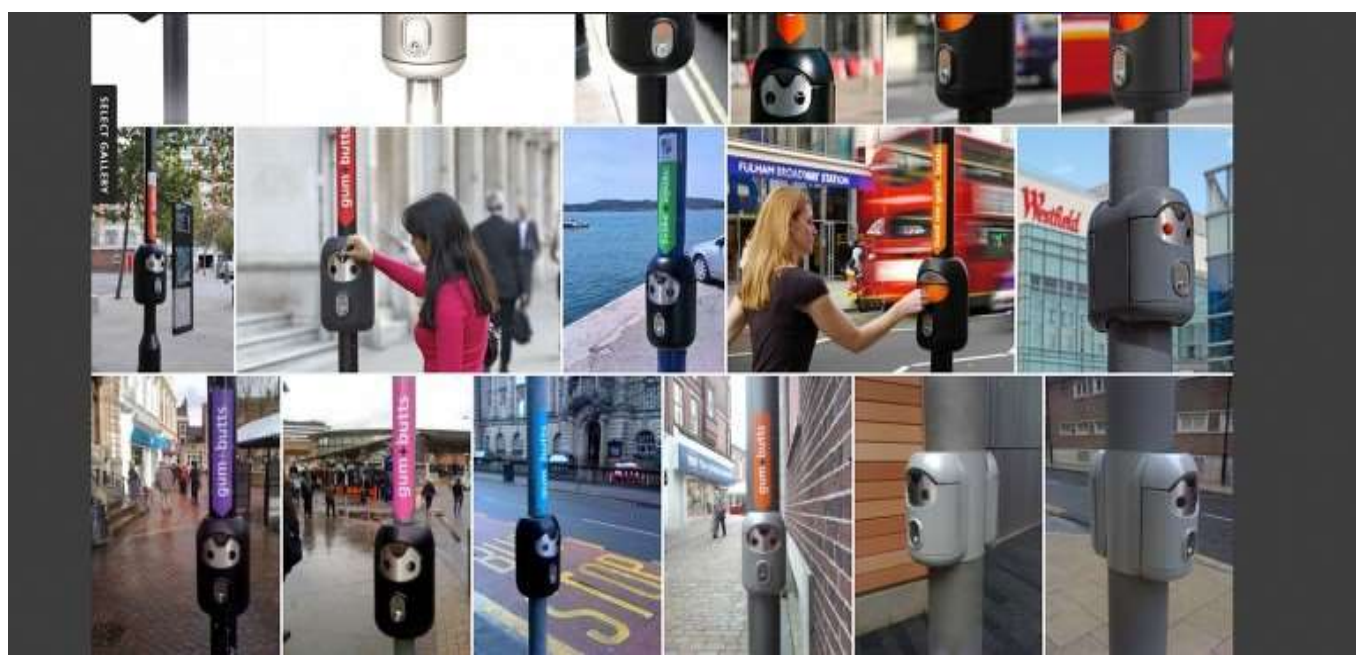

Figure 9. Multiple Smart Bins 


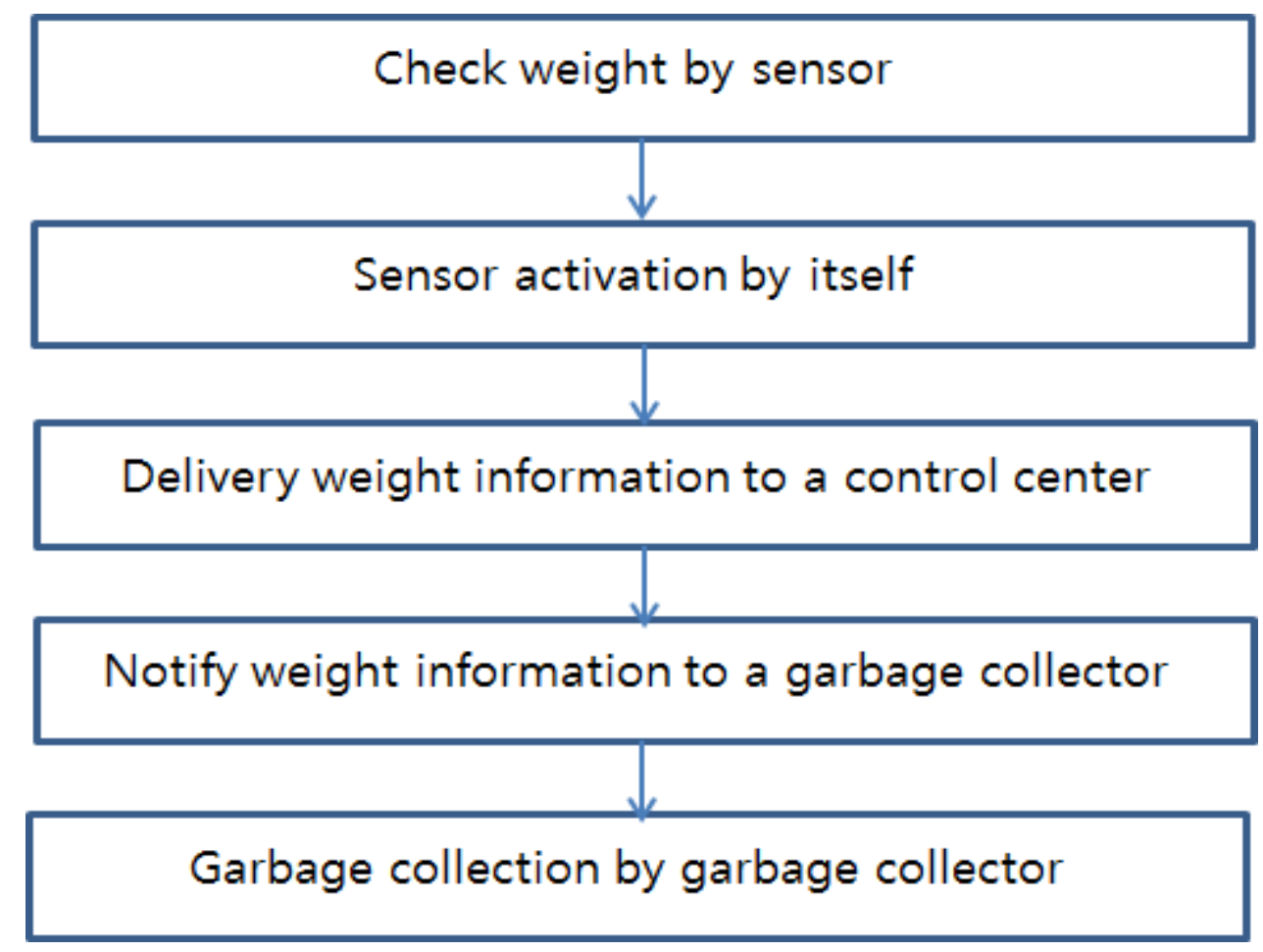

Figure 10. Concept of Smart Bin

Smart streetlight: A smart streetlight plays a role as a Wi-Fi router, and can simultaneously identify population density through noise level and air pollution. A service is offered to save electricity by controlling lighting brightness, according to the number of people, using the relevant sensor. According to the number of people, illumination brightness is enhanced, which generates pedestrian's convenience and energy saving effect. By collecting the information on voice and noise levels and movements of people in a plaza, the population density was measured. Through this, electricity can be saved with lowering lighting brightness late at night, due to sparse number of people.

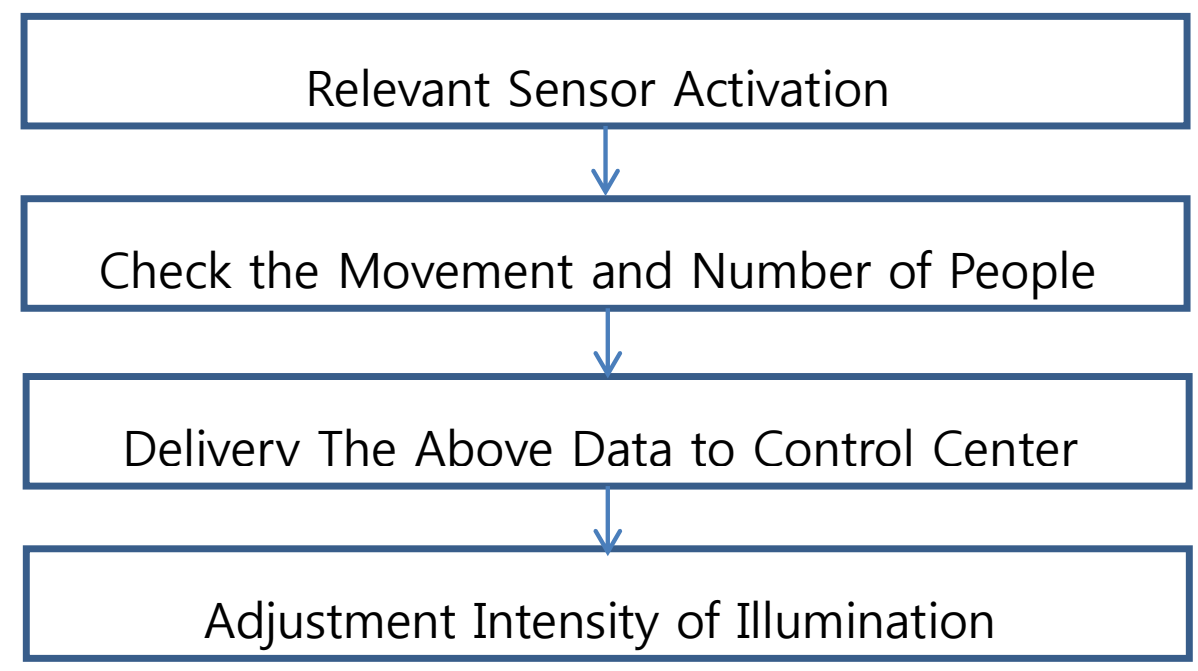

Figure 11. Saving Process of Electricity in Streetlight 


\section{Considerations}

Smart city from the industrial aspect should include various functions required for a city. Such functions include electric power, environment, transportation, education, architecture (building, factory, home), and the associated industries take on complex type. To offer city functions meeting complex functions, ICT technologies need to be essentially supported.

The technology for the sensor industry essential to IoT will be needed. For traffic function in a smart city, a function to detect and predict traffic amount should be equipped with. To prevent and eradicate crimes in a city, a function that can identify criminal behaviors is required. For the pleasant environment, there is a need to develop and use a sensor that can predict climate change. For energy efficiency optimization for buildings, the temperature of the inside of a building needs to be measured to maintain optimum temperature. To do so, a temperature sensing sensor is necessary.

The need for healthcare, due to increase in the elderly and social environment change, is rising in our society. Although a new healthcare system emerges using mobile and smartphone recently, the health information collection subjects are mostly limited to blood sugar, blood pressure and body temperature. Therefore, a technology by which a user can conveniently measure more diverse information using various bio sensors is required. To comprehensively describe, an effort to develop technologies that can store and analyze various measured information, as well as adoption of a convenient measuring mode on the part of users, should be preceded.

The interest in IoT through which information made in various devices can be shared between humans and things is recently on the rise. This study examined domestic and international industrial trends related with smart city in which IoT stands out as a major domain. The domains where such IoT can be used will be expanded continuously, and the contents are predicted to become more concrete.

\section{Conclusions}

The Internet of Things means that various devices connected to a network interact mutually. Typically, IoT is expected to offer advanced connectivity of devices, systems, and services that goes beyond machine-to-machine (M2M) communications and covers a variety of protocols, domains, and applications. When IoT is augmented with sensors and actuators, the technology becomes an instance of the more general class of cyber-physical systems, which also encompasses technologies such as smart grids, smart homes, intelligent transportation and smart cities.

The interconnection of devices is expected to usher in automation in nearly all fields, while also enabling advanced applications like a smart grid and expanding to the areas such as smart cities. We described Internet of Things related with smart city in this paper. Smart city is an urban development to integrate multiple ICT and Internet of Things solutions to control a city's infrastructures. We described actual cases of smart parking system, smart bin and smart streetlight that are parts of smart city.

\section{References}

[1] W. Alex, "The Internet of Things is revolutionizing our lives, But Standards are a must", theguardian.com. The Guardian. March, (2015).

[2] J. Holler, V. Tsiatsis, C. Mulligan, S. Karnouskos, S. Avesand and D. Boyle, "From machine to machine to the Internet of Things: Introduction to a new Age of Intelligence", Elsevier, (2014).

[3] ITU, "Internet of Things Global Standards Initiative", (2016).

[4] Harvard Business Review, "Internet of Things: SCIENCE FICTION or BUSINESS FACT?

[5] T. Lindner, "The Supply Chain: Changing at the Speed of Technology", September, (2015).

[6] A. Toma, E. Simperl and G. Hench. "A Joint Roadmap for semantic Technologies and the Internet of Things", Proceeding of the 3th STI Roadmapping Workshop, Greece, (2009).

[7] ITU, "Overview of the Internet of Things", (2012). 
[8] IDC, "The Internet of Things is Poised to Change Everything", (2013).

[9] L. Coezee and J. Eksteen. "The Internet of Things - Promise for the Future? An Introduction", IIMC International Information Management Corporation (IST-Africa 2011 Conference Proceeding), (2011), pp. 1-9.

[10] J. Gubbia, R. Buyyab, S. Marusic and M. Palaniswami, "Internet of Things (IoT): A vision, architectural elements, and future directions”, Future Generation Computer Systems, (2013), pp. 1645-1660.

[11] Pike Research, "IBM Raises the Stakes in the Smart City Technology market with its Intelligent Operations Center", (2011).

[12] Navigant Research, "Smart City", (2013).

[13] X. Chen and N. Liu, "Smart Parking by Mobile Crowdsensing", IJSH, vol. 10, no. 2, (2016), pp. 219 234.

[14] X. Zhiqing, H. Jialiana and L. Haidong, "On Research IoT-based Intelligent Parking Management System and Its Design”, IJSH, vol. 10, no. 5, (2016), pp. 217-230.

[15] D. Guisto, "Internet of Things," Springer, (2010).

[16] R. Chasta, R. Singh, A. Gehlot, R. G. Mishra and S. Chould, "A Smart Building Automation System", IJSH, vol. 10, no. 8, (2016), pp. 91-98.

\section{Authors}
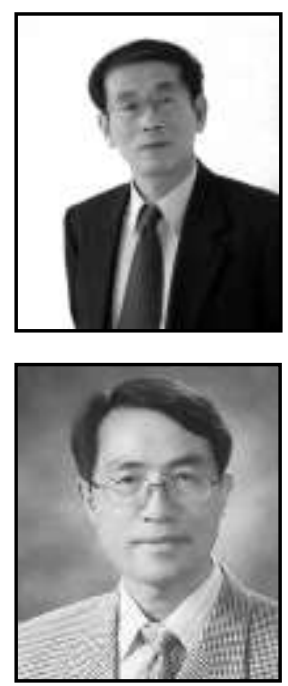

Seong-Hoon Lee, (MSc'95-PhD.'98) He received the M.Sc. degree of Computer Science and Engineering from Korea University, Seoul, Korea in 1995, and the Ph.D. degree of Computer Science and Engineering from Korea University, KOREA in 1998. Since 1998, he is a Professor in School of Information and Communication, BaekSeok University, Korea. His main research interests include Distributed system, Grid Computing, Web Service, etc.

Dong-Woo Lee, He received his BS in electronic engineering, MS in computer engineering, and $\mathrm{PhD}$ in computer science from Korea University, Korea. He joined the department of computer information science, Woosong University, Korea at 1995 . He is currently a professor. His research interests include distributed processing and systems, database, and reactive systems. 